ORIGINAL ARTICLE

\title{
BILATERAL SPHENOPALATINE GANGLION BLOCK VERSUS INTRAVENOUS CLONIDINE PREMEDICATION FOR SURGICAL FIELD IMPROVEMENT AND POSTOPERATIVE PAIN RELIEF IN ENDOSCOPIC SINO-NASAL SURGERY
}

\author{
Tarek Y Gaafar, Abeer H El Sawy, Hala E Zanfaly, Mahmoud A Abdelaziz* \\ Anesthesia and Surgical Intensive Care Department, Faculty of Medicine, Zagazig University, \\ Zagazig, Egypt
}

\begin{abstract}
*Corresponding author:
Mahmoud A Abdelaziz

Anesthesia and Surgical Intensive

Care Department, Faculty of

Medicine, Zagazig University,

Zagazig, Egypt

mahmoudgawad4@gmail.com
\end{abstract}

$\begin{array}{ll}\text { Submit Date } & \text { 2019-03-12 } \\ \text { Revise Date } & \text { 2019-04-04 } \\ \text { Accept Date } & \text { 2019-04-26 }\end{array}$

\begin{abstract}
Background: Bilateral sphenopalatine ganglion block (SPGB) and IV clonidine premedication could provide better hemodynamic parameters, surgical field, postoperative pain control during endoscopic sino-nasal surgery. Design: prospective randomized controlled comparative study. Methods: A total of 69 patients of ASA grade I or II scheduled for endoscopic sino-nasal surgery were equally divided into three groups (23 patients each): control group; block group; and clonidine group. The sphenopalatine ganglion block technique done by lateral infra-zygomatic approach guided by $\mathrm{x}$-ray fluoroscopy. Iv clonidine premedication was given $15 \mathrm{~min}$ before general anesthesia induction with dose $2 \mu \mathrm{g} / \mathrm{kg}$ as singe bolus. Surgical field quality assessment done by average category scale (ACS), hemodynamic profile and consumption of anesthetics were recorded. Postoperative pain evaluated by VAS. The time to first request for analgesia, analgesic requirement for $24 \mathrm{~h}$ postoperatively and any complications were recorded. Results: MAP and HR readings at most of intra and postoperative times, Average category scale score, intraoperative blood loss, average consumption of fentanyl and propofol and hypotensive agent (labetalol) were significantly high in control group when compared with block and clonidine groups and were significantly low in block group when compared with clonidine group except for postoperative HR. VAS score postoperatively, Time of first request of analgesia, Total pethidine consumption was significantly high in control group $\mathrm{C}$ when compared with block and clonidine groups. Conclusion: SPGB is effective for better hemodynamic control, surgical field and postoperative analgesia in endoscopic sino-nasal surgery when compared with IV clonidine premedication.
\end{abstract}

Keywords: sinus, sphenopalatine ganglion, clonidine.

\section{INTRODUCTION}

$\mathrm{F}$ unctional endoscopic sinus surgery (FESS) is the treatment modality of choice for the inflammatory disease of paranasal sinuses. Any surgery involving the nasal mucosa results in sever sympathetic stimulation, tachycardia and hypertension. These areas (nose and paranasal sinuses) are highly vascular and bleed easily which obscure endoscopic surgical field leading to prolongation of time of surgery with delayed recovery and bad surgical outcome [1-10].

SPG is an attractive site for administration of block in endoscopic sinus and nasal surgery, through blocking sensory roots. As it provides analgesic effects intra and postoperative [2].

The aim of this study was to compare the effects of bilateral sphenopalatine ganglion block versus iv clonidine premedication as 
alternative to traditional hypotensive anesthesia.

\section{METHODS}

After obtaining approval from the local Ethics committee and written informed consent from each patient, this prospective double blinded randomized controlled clinical study was carried out at the Anesthesia Department of Zagazig University Hospital from December 2016 to December 2018.

The work has been carried out in accordance with The Code of Ethics of the World Medical Association (Declaration of Helsinki) for studies involving humans.

This study is double blinded as study group member prepared the syringes and the anesthesiologist who collected the data does not know which of the patients will receive the block or premedicated with IV clonidine. The site for needle puncture for sphenopalatine ganglion block covered for all patients in both groups of the study for blindness. All patients informed about the possibility of undergoing sphenopalatine ganglion block or not according to randomization.

A total of 69 patients of both gender of ASA class I or II aged between 18 and 50 years undergoing endoscopic sinonasal surgery were enrolled in this study

Patients were excluded from the study if they had epilepsy and perceptive hearing loss, preoperative anxiety score above 5 (visual analog score for anxiety), patients were receiving beta blockers, anti-coagulants and antihypertensive medications. Also, patients receiving clonidine or benzodiazepines, neuroleptics or antidepressants two weeks prior to the study or were on chronic analgesic therapy, or had contraindications to regional nerve block. The patients were randomly allocated into three equal groups (each of 23 patients) by computerized simple random technique.

- Group C (Control group) (n=23): this group include patients operated under general anesthesia alone.

- Group B (Block group) (n=23): this group include patients who received infra-zygomatic lateral approach (C-arm guided) bilateral sphenopalatine ganglion block after induction of GA.

- Group CL (Clonidine group) (n=23): this group include patients premedicated with 2 $\mu \mathrm{g} / \mathrm{kg}$ intravenous clonidine 15 minute before induction of GA.

A study group member prepared the syringes and the anesthesiologist who collected the data did not know which of the patients received the block or premedicated with IV clonidine. The site for needle puncture for sphenopalatine ganglion block was covered for all patients in both groups of the study for blindness. All patients were informed about the risks and benefits of the enrollment in the study and the possibility of undergoing sphenopalatine ganglion block or not according to randomization.

For each patient in the three groups an $18-\mathrm{G}$ intravenous cannula was applied to a peripheral vein then premedicated with $2 \mathrm{mg}$ I.V midazolam, $2 \mathrm{~h}$ before surgery. All patients participating in the study were educated about VAS used by independent observers in the recovery area $\left(0_{-}\right.$no pain and $10_{-}$most severe pain). At the operating room, routine monitors were applied to record: ECG, heart rate (HR), mean arterial blood pressure (MAP), and oxygen saturation values.

Before the induction of anesthesia all patients received isotonic crystalloids $3 \mathrm{ml} / \mathrm{kg}$, fentanyl $1 \mu \mathrm{g} / \mathrm{kg}$ and intravenous lidocaine $1.5 \mathrm{mg} / \mathrm{kg} \mathrm{3}$ 5 min before intubation. After the application of $100 \%$ oxygen at $5 \mathrm{~L} / \mathrm{min}$ for $5 \mathrm{~min}$, anesthesia was induced with propofol $2 \mathrm{mg} / \mathrm{kg}$ and atracurium $(0.5 \mathrm{mg} / \mathrm{kg})$ to facilitate tracheal intubation by cuffed endotracheal tube and oral pack placed. Anesthesia, analgesia and muscle relaxation were maintained with propofol, fentanyl and atracurium respectively following the induction dose, higher rates of propofol infusion were generally required (150 to 200 $\mu \mathrm{g} / \mathrm{kg} / \mathrm{min}$ ) for the first 10 to 15 minutes. Infusion rates subsequently were decreased $30 \%$ to $50 \%$ during the first half-hour of maintenance. Generally, rates of 50 to 100 $\mu \mathrm{g} / \mathrm{kg} / \mathrm{min}$ in adults were achieved during 
maintenance in order to optimize recovery time, as regard fentanyl infusion rate $1-2 \mu \mathrm{g} / \mathrm{kg} /$ hour, and atracurium $0.08-0.1 \mathrm{mg} / \mathrm{kg}$ (every $25-30$ min) after initial dose to maintain analgesia and neuromuscular block respectively were given, with repeating maintenance dose as required.

The target of MAP was between $60-65 \mathrm{mmHg}$ if not achieved by propofol plus fentanyl infusion, increments of $10 \mathrm{mg}$ labetalol (sympatholytic alpha and beta blocker antihypertensive drug) was administered IV to achieve targeted MAP, when severe hypotension occurred (MAP $<55 \mathrm{mmHg}$ ), a fluid challenge (lactated Ringer's solution 3-4 $\mathrm{ml} / \mathrm{kg}$ ) and intravenous ephedrine $(5 \mathrm{mg}$ increments) were administered. Bradycardia ( $\mathrm{HR}<45$ beats/min) was treated by IV $0.3 \mathrm{mg}$ increments of atropine. At the end of surgery, neuromuscular blockade was reversed with neostigmine $0.04 \mathrm{mg} / \mathrm{kg}$ and atropine 0.01 $\mathrm{mg} / \mathrm{kg}$ and extubation was done after full recovery and awakening and ability of patients to follow verbal commands. Total dose of propofol, fentanyl and labetalol were calculated in each group.

Postoperatively, when patients suffered from pain at score equal or above 3 on VAS, they received a titrated dose of pethidine $(25-50 \mathrm{mg}$ at each dose) guided by visual analogue scale in 1st 24 hours. All patients are assessed for 1st request of analgesia and total dose of systemic analgesia required.

For the patients in block group only, after induction of general anesthesia they submitted to lateral approach (C-arm guided) bilateral sphenopalatine ganglion block.

\section{Technique of infrazygomatic (lateral approach) c-arm guided bilateral sphenopalatine ganglion block.}

Patient position

In the Block group only, the patients placed in the supine position and the head inside the $\mathrm{C}$ arm during block technique then all patients placed in a $15^{\circ}$ reverse Trendelenburg position. The needle is inserted under the zygoma in the coronoid notch. A lateral view of the upper cervical spine and mandible is obtained, and the head is rotated until the rami of the mandible are superimposed one on the other. The $\mathrm{C}$-arm is moved slightly cephalad until the pterygopalatine fossa is visualized. It should resemble a vase when the two pterygopalatine plates are superimposed on one another and are located just posterior to the posterior aspect of the maxillary sinus. The needle is directed medial, cephalad, and slightly posterior toward the pterygopalatine fossa (PPF). An anteroposterior view confirms the proper direction and positioning of the needle. The tip of the needle is advanced until it is adjacent to the lateral nasal mucosa. If resistance is felt at any time, the needle was slightly withdrawn and redirected. Cautious was taken to avoid advancing the needle through the lateral nasal wall. In lateral view, the needle was residing in the inverted vase which confirm correct placement of the needle. Once the needle is properly positioned, prior to block $0.1-0.2 \mathrm{~mL}$ of contrast agent was injected under real-time fluoroscopy to rule out intravascular spread and outline PPF for correct needle placement. Then after negative aspiration of blood or air (if the needle tip is advanced into the nasal cavity or the maxillary sinus), $1-2 \mathrm{ml}$ of $0.5 \%$ bupivacaine was injected slowly. After 5-10 minute from successful block on both sides' patient was submitted for endoscopic sinonasal surgery.

\section{Data collection}

\section{Pre and intra-operative:}

- Amount of blood loss in milliliters (collected in suction apparatus minus the normal saline used to wash the surgical cavity and by weighting of the nasal swabs).

- Quality of surgical field which measured by average category scale (table 1) every 15minute intraoperative.

- Hemodynamic profile including MAP and HR were measured before surgery (baseline), at start of surgery then every $15 \mathrm{~min}$. with assessment of surgical field.

- Amount of intravenous anesthetics used (propofol and fentanyl) and additional hypotensive agent (labetalol) requirements.

- Recovery time: the time interval between interruption of anesthetics and extubation 
- Surgery time: the time interval between mucosal incision under endoscope till nasal packing

\section{Post-operative:}

- Postoperative pain assessment by a 10-cm VAS (where 0 is defined as no pain at all and 10 as worst possible pain) at PACU, 2, 6, 12, 18 and 24 hours postoperatively.

- Postoperative analgesia requirements as regard 1st request of analgesia and total dose of pethidine needed in 1 st 24 hours.

- Postoperative nausea and vomiting (PONV). Which was measured using a categorical scoring system (None $=0$; nausea $=1$; retching $=2$; vomiting $=3$ ). Detection of nausea occurred when score $>0$ at any time point postoperatively which was managed by IV injection of $10 \mathrm{mg}$ metoclopramide.

- Postoperative complications such as dental numbness and a sense of increased retroocular pressure were recorded in the block group

Sample size: assuming that the average mean of heart rate of block group is $66.1 \pm 11.5$ (beats/min.) and that of control group is $75.3 \pm$ 14.7 so the calculated sample size is 69 patients 23 in each group using open EPI with power $80 \%$ and C.T $95 \%$.

\section{Statistical analysis}

Data were checked, entered, and analyzed using SPSS version 20. According to the type of data qualitative represent as number and percentage, quantitative continues group represent by mean $\pm \mathrm{SD}$, the following tests were used to test differences for significance, difference and association of qualitative variable by Chi square test (X2)., multiple by ANOVA or Kruskal Wallis, $\mathrm{P}$ value was set at $<0.05$ for significant results \& $<0.001$ for high significant result.

\section{RESULTS}

As regard surgery time, the control group showed the longest $(93.47 \pm 7.2 \mathrm{~min}$.), block group is the shortest $(73.04 \pm 8.6 \mathrm{~min}$.) and clonidine group intermediate $(83.3 \pm 4.6 \mathrm{~min}$.) with statistically highly significant difference (p < 0.001) (Table 2).

Average mean MAP at different times intraoperative and postoperative was significantly high in control group $\mathrm{C}$ when compared with the block group B $(\mathbf{p}<\mathbf{0 . 0 1})$ and clonidine group $(\mathbf{p}<\mathbf{0 . 0 5})$. There was a significant increase in MAP intraoperatively in clonidine group when compared with block group $(\mathrm{p}<0.05)$ but postoperatively showed no significant difference. (Table 3)

HR at different intraoperative and postoperative times was significantly high in control group $\mathrm{C}$ when compared with the block $\mathrm{B}$ and clonidine CL groups $(\mathbf{p}<\mathbf{0 . 0 1})$ till 24 hours postoperative. HR was comparable in block group B and clonidine group $\mathrm{CL}$ at all intraoperative times $(\mathbf{p}>\mathbf{0 . 0 5})$, but postoperatively block group B showed significantly low HR readings when compared with clonidine group CL $(\mathbf{p}<\mathbf{0 . 0 5})$ (Table 4)

Average category scale score was significantly higher in control $\mathrm{C}$ group when compared with the block group B $(\mathrm{p}<0.01)$ and clonidine group $C(p<0.05)$ at all intraoperative times. Also, there was a significant lower score in block group when compared with clonidine group except at $90 \mathrm{~min} .(\mathrm{p}<0.05)$ (Table 5)

Average consumption of intraoperative anesthetics fentanyl and propofol and hypotensive agent (labetalol) was significantly high in control group C TFC (total fentanyl consumption) $(247 \pm 31.68 \mu \mathrm{g})$, TPC (total propofol consumption) $(681.47 \pm 50.2 \mathrm{mg})$, TLC (total labetalol consumption) $(42.17 \pm 8.7 \mathrm{mg})$ respectively compared with the block group B TFC $(147.17 \pm 18.6 \mu \mathrm{g})$, TPC $(422.32 \pm 21.6 \mathrm{mg})$, TLC $(13.18 \pm 4.23 \mathrm{mg})$ with $(\mathrm{p}<0.001)$ and clonidine group CL TFC $(191.3 \pm 15.46 \mu \mathrm{g})$, TPC $(474.6 \pm 60.1 \mathrm{mg})$, TLC $(22.6 \pm 4.22 \mathrm{mg})$ with $(\mathrm{p}<0.05)$ (Table 6).

VAS score in the PACU room and 2, 6, 12, and $18 \mathrm{H}$ postoperatively for control group $\mathrm{C}$ was significantly high $\{4(2-5), 3.5(2-5), 4(2-5)$, $3.5(2-5)$, and $3(2-5)\}$ respectively compared with block group B $\{0(0-2), 0(0-2), 2(0-2), 2(1-$ $3)$ and $2(1-3)\}$ respectively with $(\mathrm{p}<0.01)$ and clonidine CL group $\{1(0-2), 1(0-3), 3(1-4)$, $2.8(1-4)$, and 2 (1-3)\} respectively with $(\mathrm{p}<0.05)$. there was a significant decrease in VAS in block group B at PACU time, 2, 6, 12 $\mathrm{H}$ when compared with clonidine group $\mathrm{CL}$ (p $<0.05$ ), but no significant difference at $18,24 \mathrm{H}$ 
( $\mathrm{p}>0.05$ ). At $24 \mathrm{H}$ there was no significant differences between the three groups $(p>0.05)$ (Table 7).

Time of first request of analgesia (TFA) was significantly longer in block group B (425.65 $\pm 74.6 \mathrm{~min}$.$) when compared with$ control group $\mathrm{C}(26.08 \pm 7.5 \mathrm{~min}$.) $(\mathrm{P}<0.001)$, and clonidine group CL (135.36 $\pm 21.5 \mathrm{~min}$.) (P $<0.001)$. Also, TFA was significantly higher in clonidine CL when compared with control group (p <0.05) (Table 8)

Total pethidine consumption (T.Peth.C) postoperatively was significantly high in control group C $(160.5 \pm 17.7 \mathrm{mg})$ when compared with block group B $(72.5 \pm 6.9 \mathrm{mg})$ and clonidine group CL (108.45 mg), (p $<0.001$ ), and clonidine group CL showed

Table 1. Average Category Scale (ACS).

Grade Assessment

No bleeding

Slight bleeding, no suctioning of blood required.

3 Slight bleeding, frequent suctioning required. Bleeding threatens surgical field few seconds after suction is removed.

$4 \quad$ Moderate bleeding, frequent suctioning required. Bleeding threatens surgical field directly after suction is removed

Sever bleeding, constant suctioning required. Bleeding appears faster than can be removed by suction. Surgical field severely threatened and surgery usually not possible.

Table 2. The Demographic data and surgery time of patients in the studied groups

\begin{tabular}{|l|l|l|l|l|} 
& $\begin{array}{l}\text { Group C } \\
(\mathbf{N}=23)\end{array}$ & $\begin{array}{l}\text { Group B } \\
(\mathbf{N}=23)\end{array}$ & $\begin{array}{l}\text { Group CL } \\
(\mathbf{N}=23)\end{array}$ & P value \\
\hline Age (years) & $32.65 \pm 6.94$ & $32.52 \pm 6.9$ & $29.39 \pm 6.5$ & 0.193 \\
\hline Weight $(\mathrm{kg})$ & $72.34 \pm 5.75$ & $72.52 \pm 5.9$ & $75.3 \pm 5.17$ & 0.143 \\
\hline Height $(\mathrm{cm})$ & $175.95 \pm 5.0$ & $175.9 \pm 7.62$ & $173.0 \pm 5.16$ & 0.242 \\
\hline Female/male & $13 / 10$ & $15 / 8$ & $14 / 9$ & 0.602 \\
\hline BMI & $23.57 \pm 1.42$ & $23.66 \pm 1.5$ & $24.22 \pm 1.68$ & 0.215 \\
\hline Surgery time (min.) & $93.47 \pm 7.2 \# S$ & $73.04 \pm 8.6^{*}$ & $83.3 \pm 4.6$ & 0.001
\end{tabular}

Surgery time: interval between mucosal incision under endoscope till nasal packing.

$P$ value $<0.05$ is significant 
Table 3.MAP at different times of the study between the three groups

\begin{tabular}{|c|c|c|c|c|}
\hline & $\begin{array}{l}\text { Group C } \\
(\mathrm{N}=23)\end{array}$ & $\begin{array}{l}\text { Group B } \\
(\mathbf{N}=23)\end{array}$ & $\begin{array}{l}\text { Group CL } \\
(\mathrm{N}=23)\end{array}$ & $\mathbf{P}$ \\
\hline MAP (mmHg) basal & $90.60 \pm 3.68$ & $89.56 \pm 3.99$ & $89.3 \pm 4.06$ & 0.494 \\
\hline MAP (mmHg)_ surgery start & $99.82 \pm 3.82 \# \mathrm{~S}$ & $65.26 \pm 2.39 *$ & $74.43 \pm 3.85$ & 0.001 \\
\hline MAP (mmHg) _15_min & $88.47 \pm 3.25 \# S$ & $64.65 \pm 2.28 *$ & $72.43 \pm 4.18$ & 0.001 \\
\hline MAP (mmHg)_30_min & $85.69 \pm 3.19 \# \mathrm{~S}$ & $64.3 \pm 2.09 *$ & $68.3 \pm 3.71$ & 0.001 \\
\hline MAP (mmHg)_45_min & $82.91 \pm 3.56 \# S$ & $64.6 \pm 4.6^{*}$ & $68.13 \pm 2.24$ & 0.001 \\
\hline MAP (mmHg)_60_min & $80.39 \pm 4.01 \# S$ & $64.39 \pm 4.67 *$ & $70.04 \pm 3.45$ & 0.001 \\
\hline MAP (mmHg)_75_min & $77.73 \pm 3.73 \# S$ & $63.82 \pm 3.8^{*}$ & $69.26 \pm 2.78$ & 0.001 \\
\hline MAP (mmHg)_90_min & $75.73 \pm 2.84 \# S$ & $62.65 \pm 2.16^{*}$ & $68.43 \pm 2.74$ & 0.001 \\
\hline MAP (mmHg)_surgery end & $75.04 \pm 2.97 \# S$ & $69.95 \pm 2.43$ & $69.25 \pm 3.12$ & 0.001 \\
\hline MAP (mmHg)_PACU & $87.6 \pm 7.81 \# S$ & $76.86 \pm 5.4$ & $80.3 \pm 5.2$ & 0.001 \\
\hline MAP (mmHg)_2H postop. & $88.56 \pm 5.7 \# \mathrm{~S}$ & $79.08 \pm 4.9$ & $80.8 \pm 5.18$ & 0.001 \\
\hline MAP (mmHg)_6H postop. & $88.82 \pm 6.08 \# S$ & $81.73 \pm 5.05$ & $81.73 \pm 5.44$ & 0.001 \\
\hline MAP (mmHg)_12H postop. & $87.91 \pm 4.96 \# S$ & $84.52 \pm 5.16$ & $83.13 \pm 5.14$ & 0.007 \\
\hline MAP (mmHg)_18H postop. & $90.04 \pm 4.5 \# \mathrm{~S}$ & $86.6 \pm 5.09$ & $85.21 \pm 4.93$ & 0.004 \\
\hline MAP (mmHg)_24H postop. & $88.95 \pm 4.68$ & $88.6 \pm 5.54$ & $86.69 \pm 3.92$ & 0.230 \\
\hline
\end{tabular}

$\mathrm{P \#}<0.01$ when compared control group $\mathrm{C}$ with block group $\mathrm{B}$

PS $<0.05$ when compared control group $C$ with clonidine group $C L \quad P$ value $<0.05$ is significant

$\mathrm{P}^{*}<0.05$ when compared block group B with clonidine group CL 
Table 4. HR at different times of the study among the three groups

\begin{tabular}{|c|c|c|c|c|}
\hline & $\begin{array}{l}\text { Group C } \\
(\mathrm{N}=23)\end{array}$ & $\begin{array}{l}\text { Group B } \\
(\mathrm{N}=23)\end{array}$ & $\begin{array}{l}\text { Group CL } \\
(\mathrm{N}=23)\end{array}$ & $P$ value \\
\hline HR (bpm)_Basal & $77.0 \pm 7.51$ & $77.65 \pm 5.95$ & $78.6 \pm 5.08$ & 0.683 \\
\hline HR (bpm)_S Surgery start & $93.82 \pm 7.26 \# \mathrm{~S}$ & $72.43 \pm 5.6$ & $69.78 \pm 78$ & 0.001 \\
\hline HR (bpm)_15_min & $101.0 \pm 11.1 \# \mathrm{~S}$ & $70.78 \pm 4.49$ & $71.4 \pm 6.05$ & 0.001 \\
\hline HR (bpm)_30_min & $99.34 \pm 11.9 \# S$ & $69.73 \pm 4.68$ & $71.95 \pm 4.6$ & 0.001 \\
\hline HR (bpm)_45_min & $101.69 \pm 14.5 \# \mathrm{~S}$ & $68.26 \pm 5.02$ & $69.3 \pm 6.21$ & 0.001 \\
\hline HR (bpm)_60_min & $99.47 \pm 11.1 \# S$ & $68.82 \pm 4.03$ & $70.25 \pm 6.5$ & 0.001 \\
\hline HR (bpm)_75_min & $95.43 \pm 12.2 \# \mathrm{~S}$ & $68.95 \pm 4.08$ & $69.7 \pm 6.2$ & 0.001 \\
\hline HR (bpm)_90_min & $95.26 \pm 9.38 \# S$ & $71.13 \pm 3.82$ & $72.1 \pm 4.6$ & 0.001 \\
\hline HR (bpm)_S Surgery end & $93.47 \pm 6.52 \# S$ & $73.3 \pm 5.15$ & $74.3 \pm 6.4$ & 0.001 \\
\hline HR (bpm)_PACU & $91.43 \pm 5.8 \# \mathrm{~S}$ & $71.6 \pm 6.5^{*}$ & $74.95 \pm 4.81$ & 0.001 \\
\hline HR (bpm)_2H postop. & $90.73 \pm 4.46 \# S$ & $73.08 \pm 5.5^{*}$ & $76.78 \pm 4.8$ & 0.001 \\
\hline HR (bpm)_6H postop. & $90.0 \pm 5.07 \# \mathrm{~S}$ & $74.69 \pm 4.58 *$ & $77.65 \pm 4.82$ & 0.001 \\
\hline HR (bpm)_12H postop. & $89.56 \pm 4.9 \# \mathrm{~S}$ & $75.95 \pm 4.9 *$ & $79.26 \pm 4.8$ & 0.001 \\
\hline HR (bpm)_18H postop. & $88.95 \pm 3.62 \# S$ & $77.3 \pm 4.5^{*}$ & $81.43 \pm 4.5$ & 0.001 \\
\hline HR (bpm)_24H postop. & $87.43 \pm 3.7 \# \mathrm{~S}$ & $78.6 \pm 4.6^{*}$ & $83.04 \pm 4.57$ & 0.001 \\
\hline
\end{tabular}

P\# $<0.01$ when compared control group $\mathrm{C}$ with block group B $\mathrm{PS}<0.05$ when compared control group $\mathrm{C}$ with clonidine group CL

$P$ value $<0.05$ is significant $\mathrm{P}^{*}<0.05$ when compared block group $\mathrm{B}$ with clonidine group $\mathrm{CL}$

Table 5.ACS at different times between the studied groups

\begin{tabular}{|l|l|l|l|l|} 
& $\begin{array}{l}\text { Group C } \\
(\mathrm{N}=23)\end{array}$ & $\begin{array}{l}\text { Group B } \\
(\mathrm{N}=23)\end{array}$ & $\begin{array}{l}\text { Group CL } \\
(\mathrm{N}=23)\end{array}$ & $\mathrm{P}$ \\
\hline $\begin{array}{l}\text { ACS_surgery } \\
\text { Start }\end{array}$ & $3.0(2.0-5.0) \# \mathrm{~S}$ & $1.0(0.0-2.0)$ & $2.0(1.0-3.0)^{*}$ & $<0.001$ \\
\hline ACS_15_min & $3.0(2.0-5.0) \# S$ & $1.0(0.0-2.0)$ & $2.0(0.0-3.0)^{*}$ & $<0.001$ \\
\hline ACS_30_min & $4.0(2.0-5.0) \# S$ & $1.0(0.0-2.0)$ & $2.0(0.0-3.0)^{*}$ & $<0.001$ \\
\hline ACS_45_min & $3.0(2.0-4.0) \# S$ & $1.0(0.0-3.0)$ & $2.0(0.0-3.0)^{*}$ & $<0.001$ \\
\hline ACS_60_min & $3.0(2.0-5.0) \# S$ & $1.0(0.0-3.0)$ & $2.0(0.0-3.0)^{*}$ & $<0.001$ \\
\hline ACS_70_min & $3.0(2.0-5.0) \# S$ & $1.0(0.0-3.0)$ & $2.0(0.0-3.0)^{*}$ & $<0.001$ \\
\hline ACS_90_min & $3.0(2.0-5.0) \# S$ & $2.0(0.0-3.0)$ & $2.0(0.0-3.0)^{*}$ & $<0.001$ \\
\hline ACS_surgery end & $3.0(2.0-4.0) \# S$ & $1.0(0.0-3.0)$ & $2.0(0.0-3.0)^{*}$ & $<0.001$
\end{tabular}

Data expressed as median and interquartile range

ACS: average category scale

$\mathrm{P \#}<0.01$ when compared control group $\mathrm{C}$ with block group $\mathrm{B}$

$\mathrm{PS}<0.05$ when compared control group $\mathrm{C}$ with clonidine group CL

$\mathrm{P}^{*}<0.05$ when compared block group $\mathrm{B}$ with clonidine group $\mathrm{CL}$

$P$ value $<0.05$ is significant 
Table 6.Fentanyl, propofol and antihypertensive agent (labetalol) total consumption between the studied groups

\begin{tabular}{|l|l|l|l|l|}
\hline Intraoperative & $\begin{array}{l}\text { Group C } \\
(\mathbf{N}=23)\end{array}$ & $\begin{array}{l}\text { Group B } \\
(\mathbf{N}=23)\end{array}$ & $\begin{array}{l}\text { Group CL } \\
(\mathbf{N}=23)\end{array}$ & P value \\
\hline $\begin{array}{l}\text { TFC( } \boldsymbol{\mu g}) \\
\text { intraoperative }\end{array}$ & $247.6 \pm 31.68 \# S$ & $147.17 \pm 18.6^{*}$ & $194.34 \pm 12.36$ & 0.001 \\
\hline $\begin{array}{l}\text { TPC } \\
\text { (mg)_intraoperative }\end{array}$ & $681.47 \pm 50.2 \# S$ & $422.32 \pm 21.6^{*}$ & $474.6 \pm 20.1$ & 0.001 \\
\hline $\begin{array}{l}\text { TLC } \\
\text { (mg)_intraoperative }\end{array}$ & $42.17 \pm 8.7 \# \mathrm{~S}$ & $13.18 \pm 4.23^{*}$ & $22.6 \pm 4.22$ & 0.001 \\
\hline
\end{tabular}

Data are expressed as mean \pm SD TFC: total fentanyl consumption TPC: total propofol consumption

TLC: total labetalol consumption

$\mathrm{P \#}<0.01$ when compared control group $\mathrm{C}$ with block group $\mathrm{B}$

$\mathrm{PS}<0.05$ when compared control group $\mathrm{C}$ with clonidine group CL

$\mathrm{P}^{*}<0.05$ when compared block group $\mathrm{B}$ with clonidine group CL

$P$ value $<0.05$ is significant

Table 7. VAS at different times between the studied groups

\begin{tabular}{|c|c|c|c|c|}
\hline & $\begin{array}{l}\text { Group C } \\
(\mathrm{N}=23)\end{array}$ & $\begin{array}{l}\text { Group B } \\
(\mathbf{N}=23)\end{array}$ & $\begin{array}{l}\text { Group CL } \\
(\mathrm{N}=23)\end{array}$ & P value \\
\hline VAS_PACU & $4(2-5) \# S$ & $0(0-2) *$ & $1(0-2)$ & 0.001 \\
\hline VAS_2H postop. & 3.5 (2-5)\#S & $0(0-2)^{*}$ & $1(0-3)$ & 0.001 \\
\hline VAS_6H postop. & $4(2-5) \# S$ & $2(0-2)^{*}$ & $3(1-4)$ & 0.001 \\
\hline $\begin{array}{l}\text { VAS_12H } \\
\text { postop. }\end{array}$ & $3.5(2-5) \# S$ & $2(1-3)^{*}$ & $2.8(1-4)$ & 0.001 \\
\hline $\begin{array}{l}\text { VAS_18H } \\
\text { postop. }\end{array}$ & $3(2-5) \# S$ & $2(1-3)$ & $2(1-3)$ & 0.001 \\
\hline $\begin{array}{l}\text { VAS_24H } \\
\text { postop. }\end{array}$ & $3.3(2-5)$ & $3(2-4)$ & $3(2-4)$ & 0.087 \\
\hline
\end{tabular}

Values are expressed as median (interquartile range). VAS: visual analogue scale

$\mathrm{P \#}<0.01$ when compared control group $\mathrm{C}$ with block group $\mathrm{B}$

$\mathrm{PS}<0.05$ when compared control group $\mathrm{C}$ with clonidine group CL

$\mathrm{P}^{*}<0.05$ when compared block group $\mathrm{B}$ with clonidine group $\mathrm{CL}$

$P$ value $<0.05$ is significant

\section{DISCUSSION}

The flow of blood to nasal mucosa is regulated by SPG. Thus, SPG is an attractive site for administration of block in endoscopic sinus and nasal surgery, through blocking sensory roots. As it provides analgesic effects intra and postoperative. [2]

This study found that SPGB can provide optimum surgical and anesthetic conditions 
through improving surgical field visibility, decreasing blood loss through lowering MAP and vasoconstriction of blood vessels supplying mucosa of nose and paranasal sinuses, lowering consumption of anesthetics and help to provide low heart rate and more time for venous filling and so lesser blood loss.

This study found that hemodynamic variables (MAP and HR) were better and of low values in block group $\mathrm{B}$ and clonidine group $\mathrm{CL}$ when compared with control group in all intraoperative and postoperative times till $24 \mathrm{H}$. postoperative and this achieved better hemodynamic profile. These results were in accordance with the results of Ismail et al. who reported that hemodynamic stability with SPGB group was better when compared with nonblock group [3].

Current study found that ACS significantly low in block group and clonidine group in all intraoperative times which means better surgical field visualization when compared with control group. This result was in agreement with Bhattacharyya et al. who reported that Patients of the block group showed lower ACS compared with the control group. which was statistically significant [4].

Jiwanmall and colleagues studied intravenous clonidine as a part of balanced anesthesia for controlled hypotension in functional endoscopic sinus surgery and found that clonidine group had an excellent field of surgery [5].

In another study done by Wawrzyniak and his associates, to evaluate improved quality of surgical field during endoscopic sinus surgery after clonidine premedication and reported that evident reduction in surgical field bleeding was most likely related to an activation of peripheral alpha1 adrenergic receptors by clonidine, resulting in peripheral vasoconstriction [6].

This study showed Average consumption of intraoperative anesthetics fentanyl, propofol and hypotensive agent (labetalol) were significantly high in control group when compared with block group and clonidine group. These results were in agreement with Ahmed and Abu-Zaid who stated that Intraoperatively, isoflurane consumption was less in block group than non-block group. All patients in the non-block group required supplemental esmolol to achieve the target MAP. 1n contrast only 2 patients in the block group required supplemental esmolol [7].

The present study showed that bilateral sphenopalatine ganglion block had excellent postoperative analgesic effect in endoscopic sinonasal surgery and these proved by the results of VAS score which were low in the block and clonidine groups when compared with control group. These results were matched with the results of the study done by Bhattacharyya and associates. [4]

Against the results of this study, the study done by Demaria et al. who reported that despite better recovery times and faster discharge, there were no significant differences between block group and control group as regard pain intensity and satisfaction with pain. But these results differences may be attributed to different technique of sphenopalatine ganglion block and different local anesthetic used as Demaria et al. used palatal approach for the block technique and lidocaine $1 \%$ injection as local anesthetic used while this study used infrazygomatic lateral approach C-arm fluoroscopy guided technique and bupivacaine $0.5 \%$ as local anesthetic which is more potent and longer acting [8].

Study done by Ahmed and Abu-Zaid to evaluate the role of endoscopic sphenopalatine ganglion block in sinonasal surgery, showed that recovery time was significantly lower in the block group $(7.23 \pm 1.56 \mathrm{~min}$.) when compared with nonblock (control) group $(9.45 \pm 3.34 \mathrm{~min}$.) and this matched with the results of our study [7].

This study showed that Time of first request of analgesia (TFA) was significantly longer in block group B when compared with control group $\mathrm{C}$ and this explained by good analgesic effect of bilateral sphenopalatine ganglion block. These results were in accordance with the results of Demaria et al. who reported that TFA in patients received sphenopalatine ganglion block in endoscopic sinus surgery under general anesthesia was significantly 
longer when compared with the patients in the control group. [8].

This study revealed that postoperative analgesic requirements (total pethidine consumption) was significantly high in control group $\mathrm{C}$ when compared with block group B. These results were in agreement with the results of Ismail et al. who revealed fewer patients required additional analgesics throughout the postoperative period in the block group compared to the non-block group during the first 24 hours postoperatively [3].

In the present study the amount of blood loss was significantly high in control group when compared with block group and clonidine group. These results were in agreement with Bhattacharyya and his colleagues who stated that blood loss was significantly greater in the control group compared with the sphenopalatine ganglion block group [4].

As regard postoperative nausea and vomiting this study showed that number of patients with postoperative nausea was significantly high in patients of control group when compared with block group and clonidine group. These results were in agreement with the study done by Ismail et al. who reported that the incidence of postoperative nausea and vomiting were significantly higher in control group (15 from total 30 patients) versus block group (6 from total 30 patients) [3].

Also, Bhattacharyya et al. found that minor anticipated postoperative complications such as dental numbness and sense of increased intraocular pressure in the block group and were managed with reassurance only and these results were in accordance with the results of the current study [4].

This study had some limitations:

- The first limitation is that only a small number of patients were enrolled

- The second was GA was used as baseline in all groups which likely biased the anesthetic effects of SPGB.

- $\quad$ SPG block need skill and experience.

\section{CONCLUSION}

Bilateral sphenopalatine ganglion block under general anesthesia can provide better hemodynamic control, less blood loss, good surgical field with prolonged postoperative analgesia, and early recovery with minor complications so can be used safely along with general anesthesia in FESS.

Intravenous clonidine premedication as a single bolus dose, is effective in achieving better hemodynamic profile when used with balanced anesthesia in FESS and reduces the intraoperative requirement of additional fentanyl, propofol and labetalol. It effectively reduces the intraoperative blood loss and provides a dry operating field. Clonidine also provides good analgesia without any significant side effects such as sedation, hypotension and bradycardia. So, clonidine can be used as alternative for SPGB for patient who refuses the procedure or for any other contraindication as difficult technique or unavailability of equipment's of the procedure as c-arm or IV dye.

\section{Declaration of interest}

The authors report no conflicts of interest. The authors alone are responsible for the content and writing of the paper.

Funding information:None declared

\section{REFERENCES}

1. Cochran C.S, Marple, and Bradley F (2014). Nasal functions can be altered or impaired by structural or functional abnormalities arising from sinonasal disease processes Dallas Rhinoplasty: Nasal Surgery by the Masters, Third Edition, page no. 45.

2. Bratbak D.F, Daniel F, and Nordgard S (2015). Treatment of headache by injection of neuroinhibitory substance to sphenopalatine ganglion or otic ganglion. U.S. Patent Application no 14/426,303.

3. Ismail S.A, Salah A., Hisham M.F, and Anwar H.M (2005). Bilateral sphenopalatine ganglion block in functional endoscopic sinus surgery under general anesthesia, Alexandria Journal of Anesthesia and Intensive Care-vol. 8, page no. 4.

4. Bhattacharyya S, Tewari M.K, Ghosh S, Chakroborty J, Das W, and Barman U (2016). Evaluation of the efficacy of bilateral sphenopalatine ganglion block in endoscopic sinus surgery under general anesthesia: a randomized prospective controlled trial." 
Research and Opinion in Anesthesia and Intensive Care, vol. 3, issue 4, page no. 173-178.

5. Jiwanmall M, Joselyn A.S, and Kandasamy S (2017). Intravenous clonidine as a part of balanced anesthesia for controlled hypotension in functional endoscopic sinus surgery, Indian Journal of Anesthesia, vol. 61, issue 5, page no. 65.

6. Wawrzyniak, K, Burduk P.K, Cywinski JB, Kusza K, and Kazmierczak W (2014). Improved quality of surgical field during endoscopic sinus surgery after clonidine premedication - a pilot study." International forum of allergy \& rhinology. vol. 4. issue. 7. Wiley-Online library, page no. 542-547.

7. Ahmed H.M and Abu-Zaid E.H (2007). Role of intraoperative endoscopic sphenopalatine ganglion block in sinonasal surgery." J. Med Sci (JMS (ISSN 1682-4474) international scientific journal) vol. 7, page no. 1297-1303.

8. Demaria J.R, Samuel, Govindaraj S, Chinosorvatana N, Kang S, and Levine A.I
(2012). Bilateral sphenopalatine ganglion blockade improves postoperative analgesia after endoscopic sinus surgery, American Journal of Rhinology \& Allergy, vol. 26, issue 1, page no. e23-e27

9. Boezaart A.P, VanderMerwe J, and Coetzee A (1995). Comparison of sodium nitroprussideand esmolol-induced controlled hypotension for functional endoscopic sinus surgery. Canadian journal of anesthesia; vol. 42, 5, page no. 373376.

10.Milewski C. (1996). Endoscopic endonasal ethmoidectomy in acute therapy refractory sinusitis. Larygo-rhino-otologie, vol. 75, page no. 286-289.

11. Srivastava U, Dupargude A.B, Kumar D, Joshi K, and Gupta A (2013). Controlled Hypotension for Functional Endoscopic Sinus Surgery: Comparison of Esmolol and Nitroglycerine, Indian Journal of Otolaryngology and Head \& Neck Surgery.vol. 65, issue 2, page no. 440-444

To Cite This Article: Tarek YG, Abeer HE, Hala EZ, Mahmoud AA*. Bilateral sphenopalatine ganglion block versus intravenous clonidine premedication for surgical field improvement and postoperative pain relief in endoscopic sino-nasal surgery.ZUMJ 2019;25(6);847-857.DOi: 10.21608/zumj.2019.10470.11030. 